\title{
Research on the Teaching Mode of College Music Education Turning Class Based on MOOC
}

\author{
Mao Yingxin \\ (Qilu Normal University Jinan, Shandong Province 250000) \\ 1393158666@qq.com
}

\section{Keywords: MOOC; Flip classroom; College; Music education}

\begin{abstract}
Since the opening of the "MOOC" era in 2012, MOOC has triggered a "digital tsunami" in education. The construction of the MOOC platform in China has also developed rapidly. While developing rapidly, it is impossible to support students to complete the individualized learning of the whole subject according to their hobbies and their own rhythm. It is unable to meet the selective needs of students to complete an online course according to their hobbies and at their own pace, due to their own existence. The inevitable problem, MOOC is also controversial. In order to solve the problem, this paper proposes an efficient music flipping mode based on MOOC, which no longer exists in the form of purely independent MOOC teaching, but combines the flipping classroom teaching mode to make the online course and offline course closely combine and influence each other.
\end{abstract}

\section{Introduction}

Under the conditions of the new era, the infinite demand of human beings is ingeniously connected with massive information. Mobile Internet, big data, cloud computing, intelligence and modern manufacturing are perfectly combined. People live freely between virtual and reality, sharing the rapid development. The information, information and knowledge brought about by the Internet technology revolution are looking forward to the infinite possibilities of being transformed into reality. Corresponding to the rapid development of Internet technology, the curriculum form, teaching mode and learning style of college music education are also changing. MOOC and flip classroom have become a new form of reform and transformation of teaching and learning methods. In the music teaching of colleges and universities, the application of MOOC brings a series of positive promotion effects to music education. The construction of MOOC platform, the introduction of courses, and the integration of high-quality teaching resources make the scientific and technological achievements of the information age more and more benefit the music classroom. To promote the quality and effectiveness of music teaching in ordinary colleges and universities has been significantly improved. In the information environment, teachers provide learning resources with teaching videos as the main form. Students complete the viewing and learning of teaching resources such as teaching videos before class. Teachers and students complete homework questions, collaborative inquiry and interaction in the classroom. A new teaching model for activities such as communication. It subverts the traditional teaching organization and realizes the transformation based on the "student-centered" teaching philosophy.

\section{The Design Concept of MOOC}

\section{To Digital Network Resources for Curriculum Development Philosophy.}

The development of online courses and digital resources requires the integration of all elements that can serve the objectives and objectives of the course, including new equipment, video and audio, and the student's existing experience and learning ability. Curriculum resource development should be based on clear teaching objectives and in-depth exploration of course content, understand the learner's existing experience and learning ability, pay attention to the society's demand for talent 
training, focus on the latest content and cutting-edge technology to supplement the generative resources.

Broaden Horizons, Explore Innovation, and Form New Ideas and Methods for Curriculum Resource Construction.

The application of cutting-edge technology puts forward higher requirements for the construction of MOOC courses. Explaining a knowledge point is only one of the most basic and minimum requirements of the MOOC course. Curriculum developers have the dual roles of curriculum construction, knowledge transfer and teaching research. Therefore, we must constantly broaden our horizons and follow the technological changes. We will continue to add cutting-edge technology and the most advanced ideas in the construction of curriculum resources, try new ideas and explore new ones. method.

Reasonable Design of Curriculum Resources Construction Program.

Since big data and network cloud contain rich curriculum resources, based on the improvement of quality, a reasonable curriculum resource construction plan should be formed. The design of the program should be based on the update of Internet technology and the new situation, new tasks and new requirements of the curriculum reform, including the development and design ideas of the curriculum team, technology and method, as well as the curriculum objectives, syllabus, teaching plan, study guide, teaching Courseware, teaching materials, teaching implementation and other aspects of the design. Under the guidance and guidance of high-level design solutions, the quality of MOOC courses will continue to improve in scientific planning, self-regulation and maintenance.

\section{The Status Quo of Music Elective Courses in Colleges and Universities}

Ordinary colleges in the form of public elective courses, with quality education as the core to popularize and enrich the knowledge of college students' music culture. As an important aesthetic art, music is very popular among college students, and music lessons have become popular elective courses. However, students feel that the teaching process is boring, the effect of teaching is not up to the expectations of students, causing students to like music, but do not like the embarrassing situation of music lessons. There are three main reasons for this:

\section{Lack of Teaching Resources}

Due to the neglect of art education in Colleges and universities, the investment in music teaching resources is relatively small, there is no special music classroom, teaching equipment is not complete. The scarcity of resources is also reflected in the weakness of teachers. Music elective course is an art elective course with a wide range of audiences. Most colleges and universities are generally faced with the problem of weak teachers. Take our school for example, there are only three full-time music teachers. Faced with a large number of art courses, the teaching tasks of the three teachers are very heavy. Under the heavy teaching task, teachers have to face all kinds of administrative affairs of the school, and their time and energy to think about and study related teaching problems are very limited. Some courses depend on part-time teachers, but part-time teachers have limited energy because of their part-time status, which makes the quality of music teaching difficult to be guaranteed.

\section{The Student's Music Level is Uneven}

As an elective course, the music class is aimed at the whole school. There are no pre-requisites, and there is a gap in the student's music foundation. The music level of each class is uneven and the demand for music knowledge is different. It is a hindrance to music teaching, and it is difficult to engage in all-round and personalized education. Teachers facing students with uneven music levels can only use the "compromise" approach to teaching, which leads to some students with better foundations not getting more improvement, and students who have weak foundations can't understand. These are all important reasons that affect the effectiveness of teaching and students' interest in learning.

\section{Theoretical Teaching and Artistic Practice}

As an art course, teachers need to emphasize the artistic experience, and in the practical experience, students can obtain artistic aesthetics and improve their comprehensive quality. At 
present, most of the music teaching in colleges and universities separates theoretical teaching and artistic practice. This is especially true in non-music colleges and universities. The theoretical teaching is aimed at students without artistic specialties or non-artistic students, while the main subjects of artistic practice activities are Artistic specialty and students selected for the Art Troupe. If art education is out of the practical experience, it will not achieve the purpose of art education. This is the main reason why students like to participate in art activities and like to play music, but do not like music lessons.

\section{Based on the Significance of the Flipped Classroom MOOC}

\section{MOOC Support Flipped Classroom Will Help Students Higher Order Thinking.}

Based on MOOC 's flipping classroom, the pre-class rich online courses make students' learning completely independent. Students in the class can choose to participate in classroom collaborative inquiry activities, through discussion and communication between teachers and students and students (including results display) and evaluation (Learning activities such as student mutual evaluation) develop advanced thinking skills. MOOC the flipped classroom provides a powerful set of differentiate teaching and individualized learning in one, learners develop hobbies, self-paced learning and more time and energy to develop its own high-level thinking skills (including creativity) based Systematic platform support. On the macro level, for the student group and even generations, they can fully use more time and energy to develop advanced thinking ability and increase the output of innovative talents on a large scale, as shown in Figure 1.

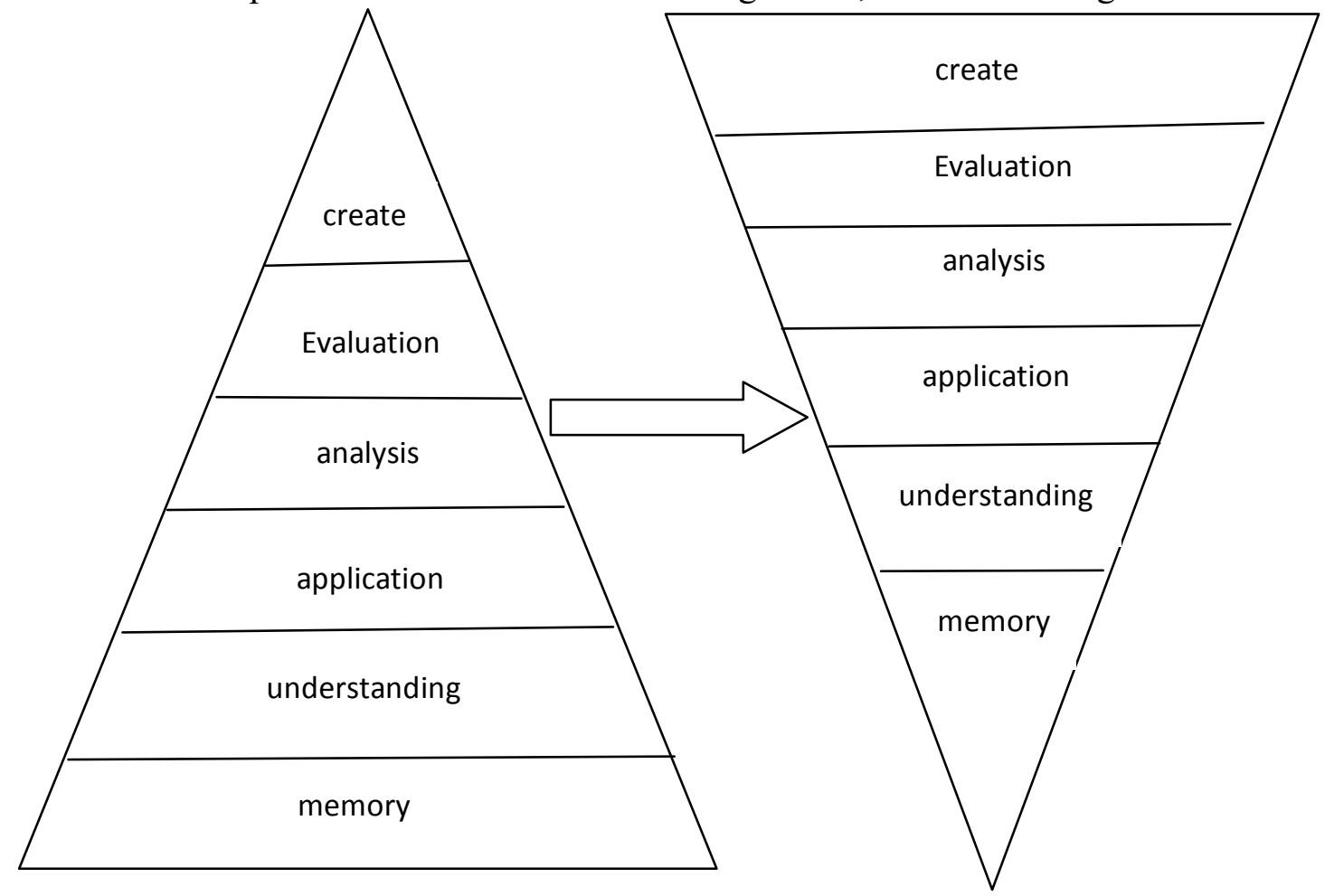

Figure 1 is based on the educational goal of the MOOC flipping classroom "flip"

\section{MOOC- Supported Flip Classrooms are More Able to Practice the "Skilled Teaching Method."}

Flipping the classroom is an effective strategy for implementing differentiated teaching. The core content is called "skilled teaching method", and its core philosophy is: "As long as the teaching conditions can meet the needs of the students, then all students can master the knowledge, and no students will fall behind or have poor grades." The Winnetka plan has caused a great sensation, and the teaching reference books for students' self-study are in short supply. Not long after, the sophisticated teaching method was gradually forgotten by people and even abandoned altogether. The reason is that the sophisticated teaching method needs to provide students with paper learning materials that cost huge human and financial resources. The general low level of economic 
development in various places limits the popularity of this new educational concept. Second, the sophisticated teaching method requires teachers to master. With a variety of different technologies and skills, teacher training barriers have prevented a large number of teachers from meeting this requirement.

In fact, from the United States, Canada, Australia, Singapore and other developed countries in recent years to implement MOOC- based flip classroom research and practice results, has summarized the following seven aspects, namely: 1 student's academic quality has improved significantly; 2 learning motivation significantly enhanced 3 teacher-student relationship is more closely; 5 students learn more autonomy; 5 students' disciplinary problems are obviously improved; 6 teachers' job satisfaction is improved; 7 schools have closer relationship. The achievement of these achievements has further promoted the development of the flipping classroom based on MOOC.

\section{Based on the Flipped Classroom Teaching Model MOOC}

MOOC-based flip-flop classroom has some shortcomings in the aspects of systematic and optional curriculum content, academic track generation and large data mining, online feedback and evaluation of learning effect, etc. As a remedy, the flip-flop classroom based on MOOC satisfies the personalized learning requirements of students (pre-class and in-class). The structure of flipped classroom teaching based on MOOC is presented, as shown in Figure 2.

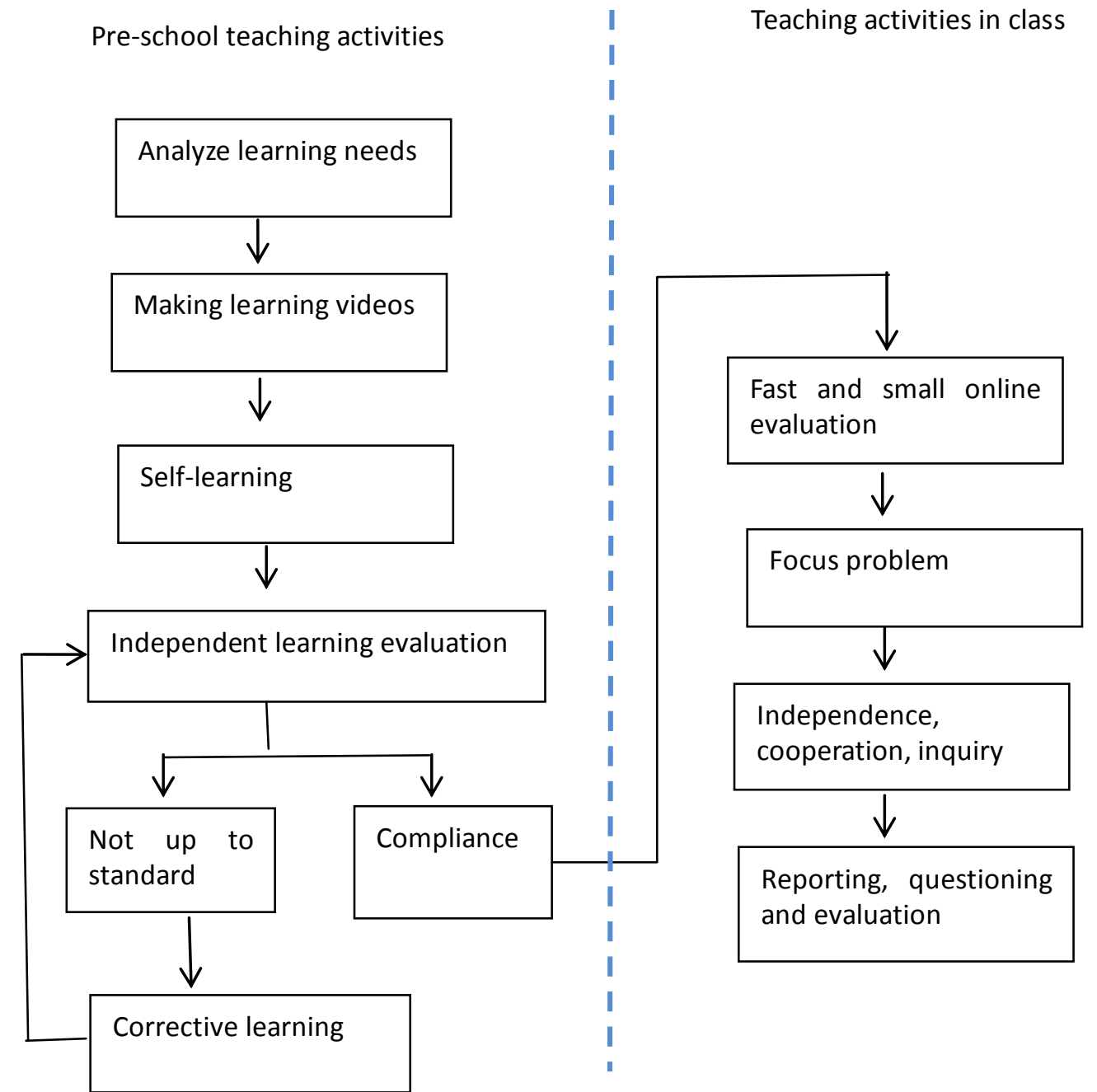

\section{Selection of MOOC Teaching Resources Before Class}

The selection of teaching resources is the first step in teaching. At present, there are mainly three types of MOOC teaching platforms introduced in China: 
The first is the three foreign MOOC websites (Udacity, Coursera, edX). The courses in these three network resource platforms are mainly taught in English. If they are directly introduced into foreign classrooms, they will cause some obstacles in cultural background, language and acceptance.

The second kind is the domestic development of network teaching resources, such as MOOC courses in Chinese universities, national quality resources sharing courses, Netease open courses, etc. The domestic network teaching platform is more suitable for China's national conditions and teaching needs, in line with the actual teaching and management status of higher education in China.

The third kind is the network course that each university independently develops and records according to the student's condition and demand, this kind of course resource is only open in the scope of the school. If the financial and human resources are insufficient, there may be some problems in the adaptability and compatibility, which consumes the energy of our teachers and requires a high level of research and development technology.

Under the background of MOOC, the network resources selected for the teaching mode of flip-flop classroom should be mainly the network teaching resources developed in China, and different types of resources should be supplemented according to the school situation and students' needs. In the pre-class knowledge subject learning knowledge, at least in cultural background and language aspects will reduce some difficulty, students are easy to enter the learning state. Taking music elective course as an example, the content and resources of music network course are less than other courses. Teachers should try to choose the network resources developed in China, especially some knowledge about Chinese traditional music culture. Foreign resources play a very important role in our understanding of foreign music culture. Some music appreciation courses do not explain much in theory, but play more music audio-visual materials. Teachers can use these rich audio-visual materials as supplementary resources to introduce Chinese and Western culture to students by using foreign music explanations.

\section{Teaching Activity Design in Class.}

Quick and small tests first can not only activate students' thinking, but also help to present practical problems that need to be studied and solved. Usually, there are a variety of problems to be solved, and the time in class is extremely limited. Teachers need to guide students to sort out and focus on many problems, find out the key problems, and then guide students to conduct in-depth and extensive discussions. General problems are solved through "peer assistance" and difficult problems are guided by teachers. Finally, students need to improve their thinking quality and develop their innovative ability by presenting, questioning or evaluating the research results.

\section{Comparison of Method Validation}

Through the course design, compared with the traditional teaching and the application of MOOC-based flip-flop classroom teaching, students' ability to absorb music curriculum knowledge increased significantly, as shown in Figures 3 and 4. 


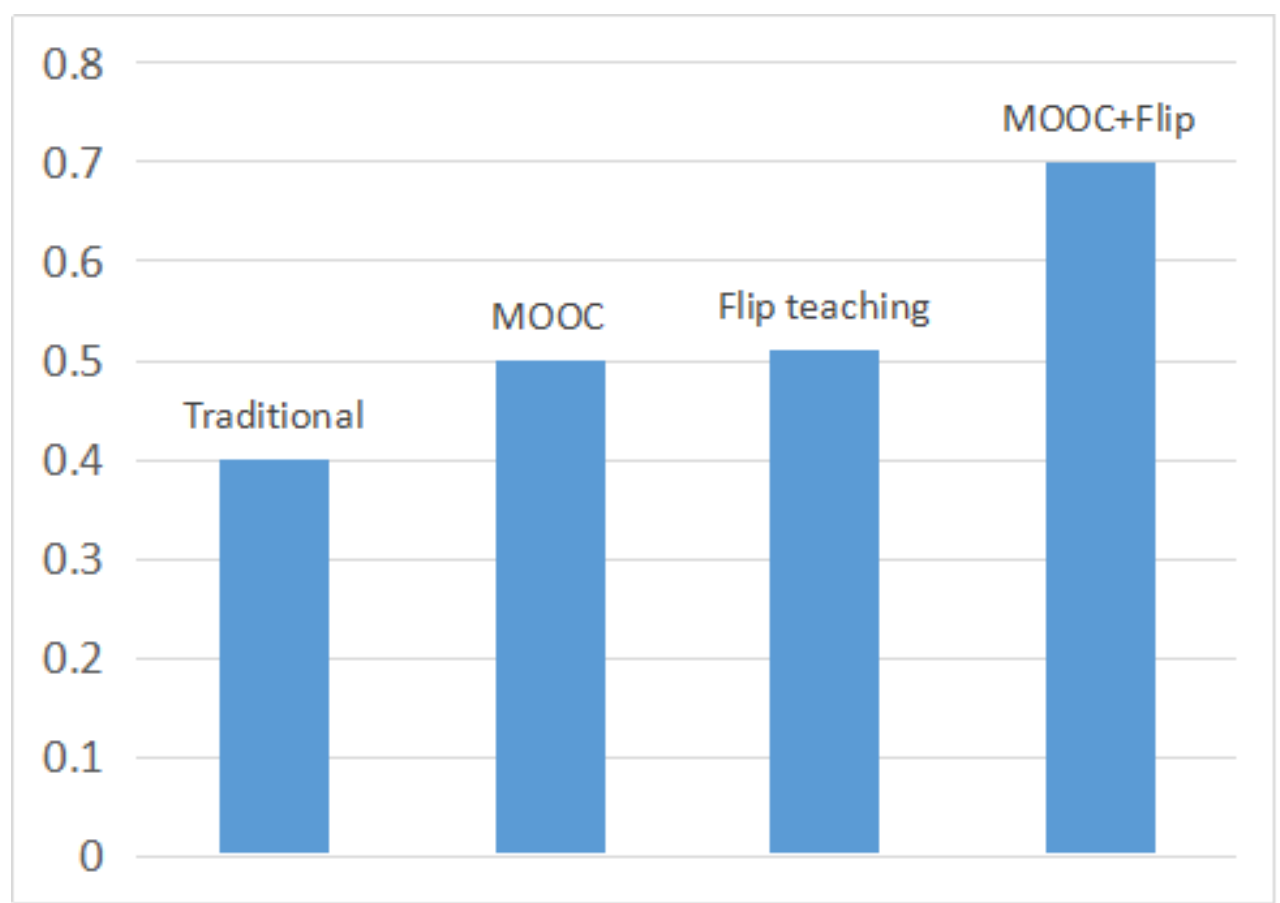

Figure 3 Teaching method knowledge absorption rate comparison histogram

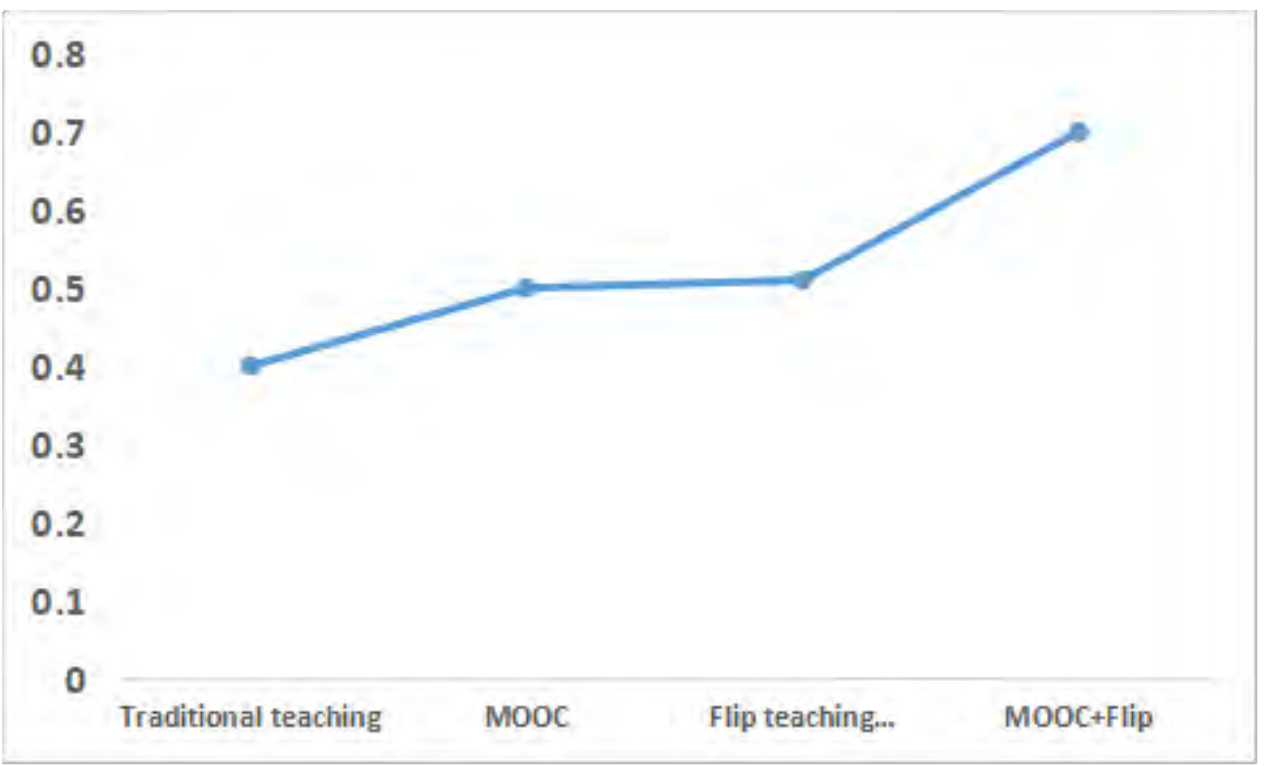

Figure 4 teaching method knowledge absorption rate comparison line chart

New research methods make students' knowledge absorption faster and the concentration of class is higher.

\section{Conclusion}

In the field of basic education, liberating learners from the pursuit of test scores or academic qualifications is a prerequisite for the thorough implementation of quality education and lifelong learning concepts. In the Internet age, high-quality teaching videos can solve the problem of pre-class learning content in the flipping classroom, but there is no flipping classroom supported by MOOC, that is, there is no online course that can cover the whole subject, and the normalized flipping classroom effect will not be achieved. Reshaping the school teaching structure is an empty talk. In other words, the number and inferiority of online courses will directly determine the effectiveness of flipping the classroom, determine whether students can achieve independent and individualized learning, and decide whether to cultivate new talents on a large scale. The MOOC- 
based flip classroom is an indispensable new teaching model for modern schools. The MOOC music course combined with the flipping classroom can maximize the advantages of both, more effectively improve the quality and efficiency of the teaching and learning of music courses, actively and effectively carry out the music curriculum of colleges and universities, and give full play to the value and influence of music education.

\section{References}

[1]Zhu T, Zhang L. Flip classroom design and implementation of the literature retrieval course network teaching platform[C]// International Conference on Computer Science \& Education. IEEE, 2015:1005-1008.

[2]Chen Y X. Flip Classroom Teaching Reform Practice of Circuit Principle Based on The MOOC[J]. Journal of Electrical \& Electronic Education, 2016.

[3]Wan M. The application of flip classroom mode based on micro class in college English teaching $[\mathrm{J}]$. Journal of Jiamusi Vocational Institute, 2015.

[4]Lan W U. Based on the SPOC the Application Research of Flip Classroom Teaching Mode in Higher Vocational Curriculum[J]. Computer Knowledge \& Technology, 2016.

[5]Liu S W, Jun L I, Liu S J, et al. Discussion of Internet + Blended Teaching about MOOCs,SPOC and Flip Classroom[J]. Education Teaching Forum, 2016.

[6]Liu K. Design of Flip Classroom Teaching Mode under "Internet +"[J]. Journal of Huanggang Polytechnic, 2017.

[7]Zhang X, University N X. A study on the teaching mode of applying "MOOCs + Flip Classroom" in college physical education[J]. Liaoning Sport Science \& Technology, 2017.

[8]Zheng K. The Technical Orientation and Avoidance of College Music Classroom Teaching[J]. Theory \& Practice of Education, 2016.

[9]Wang F, Liu X Y, Liu B. Teaching Reform and Practice of College Theoretical Mechanics Course Based on Flip-up Classroom[J]. Education Teaching Forum, 2017.

[10]Dhokai N. Pedagogical Ideas on Sonic, Mediated, and Virtual Musical Landscapes: Teaching Hip Hop in a University Classroom.[J]. International Journal of Music Education, 2012, 30(2):111-119.

[11]Wang L. The Study on the Application of Flip-flop Classroom Teaching Model in the College English Teaching[J]. 2017(icsste).

[12]Yao Y. On the Effect and Integration of MOOC for China Higher Education of Music[J]. Journal of Yunmeng, 2015.

[13]Sun Z, Liu J, Liu Z. The Application of Discovery Teaching in College Music Education Based on Marginal Utility and Regression Model[J]. Chemical \& Pharmaceutical Bulletin, 2013, 50(10):1373-5.

[14]Shu-Hao M A, Liu H. Practice and Integration of the Musical Culture of Minority into College Music Major Course[J]. Heilongjiang Researches on Higher Education, 2016.

[15]Zhang G H, Hong-Quan L I, Zhang Y, et al. Exploration on the Reform of Classroom Teaching in the Course of Ideological and Political Education in Colleges and Universities[J]. Journal of Hubei Correspondence University, 2017.

[16]Wang H. An Empirical Study on the Vocational College English Flipped Classroom Instructional Model Based on Cloud-Based Teaching Class[J]. Modern Education Journal, 2016.

[17]Liu Y, Zhao J, Department E. An Analysis on Layered-“Flip Classroom"Teaching Mode in Spoken English Class of College[J]. Overseas English, 2016.

[18]Shu C, Min L, Wan H F. On College Mathematics Teaching Based on Reverse of Classroom Teaching Mode[J]. Journal of Southwest China Normal University, 2017.

[19]Liu Q. Taiwan Flip Classroom Practice Enlightenment to the Curriculum Reform of College English[J]. Education Teaching Forum, 2018.

[20]Deng J, University C. Research into the Flip Classroom Teaching Model in the College Aerobics Course[J]. Journal of Chengdu University of Traditional Chinese Medicine, 2018. 